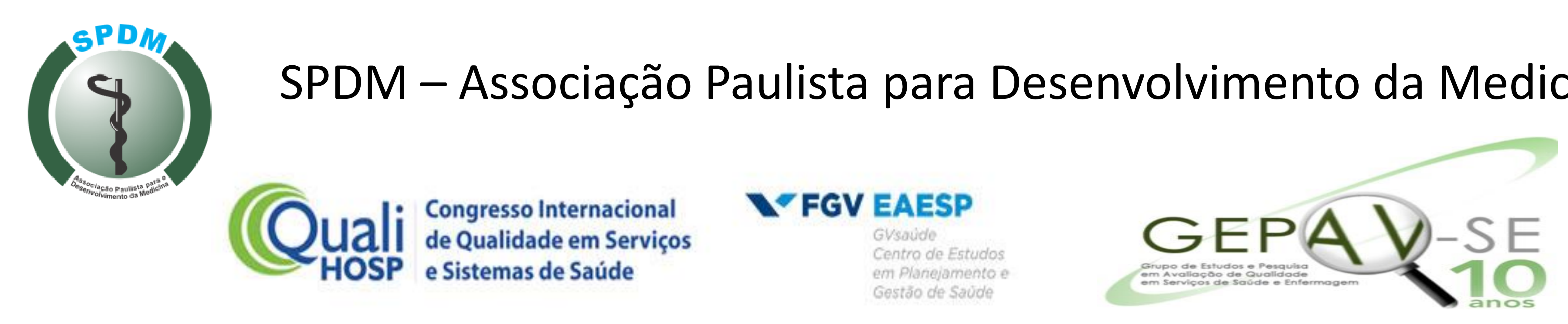

Elisabeth Akemi Nishio, Cristiane Aparecida Betta, Fabiana de Oliveira Alves, Maria D'Inocenzo

\title{
Avaliação da Experiência do Paciente Após Internação Em Um Hospital Público.
}

Eixo temático: Avaliação e Qualidade do Cuidado

Introdução: Com a mudança do mercado para modelos de cuidado baseados no valor e centrados no paciente, melhorar a experiência do paciente é um foco cada vez mais comum para os hospitais1. Os escores de experiência do paciente - refletindo fatores tão diversos quanto o nível de ruído do piso do hospital durante a noite e o quanto os enfermeiros e médicos se comunicam com os pacientes - tornaram-se medidas-chave de desempenho do hospital2 ${ }^{2}$. Assim experiência do paciente inclui vários aspectos da prestação de cuidados de saúde ,permitindo que as organizações de saúde foquem seus esforços no que importa para eles e não apenas no que é o problema junto a eles. Objetivo: Mensurar a Experiência no Cuidado através da Experiência do Paciente e Identificar Oportunidades de Melhorias. Método: Estudo retrospectivo, quantitativo, realizado em um hospital público de grande porte localizado na região metropolitana de São Paulo, gerido por uma Organização Social de Saúde. Para avaliação da Experiencia do Paciente foi aplicado o Questionário HPAHCS (Avaliação do Paciente Hospitalar relativamente aos Sistemas e Prestadores de Cuidados de Saúde) no período de outubro a novembro de 2018 para os pacientes que estavam de alta hospitalar e aceitaram participar da pequisa.
Resultado: A amostra foi composta por 50 pacientes , 56\% sexo masculino média de idade de 48 anos. Na perpectiva estrutura e instalações $56 \%$ consideraram como adequado.90\% necessitou de medicação para dor durante a hospitalização sendo $78 \%$ considerou sua dor bem controlada . $80 \%$ dos pacientes recomendaria o hospital para amigos e familiares

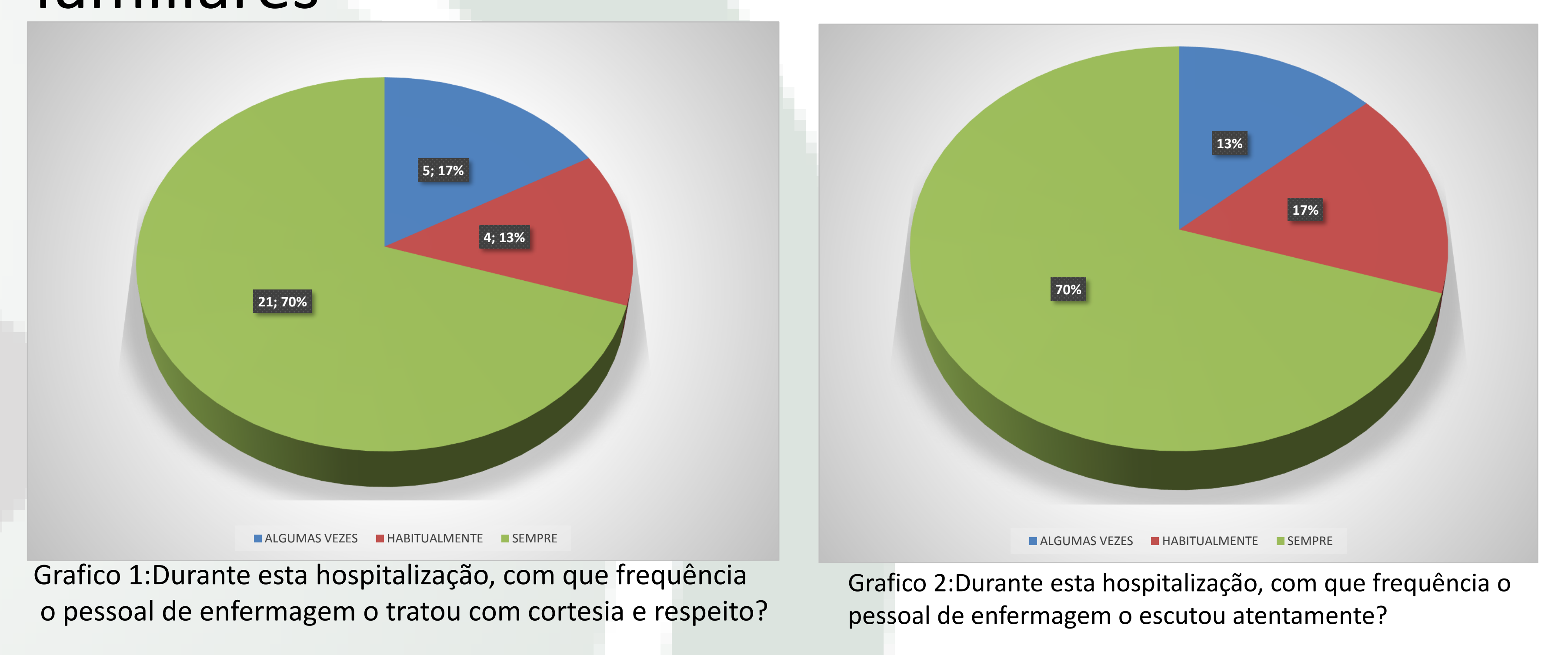

Conclusão: O resultado Questionário de Experiencia do Paciente reforça as ações de Cuidado Centrado no Paciente e a importância de focar em melhorias no ambiente físico da instituição. Esse método nos proporciona avaliar não apenas o resultado do tratamento, mas também a percepção do paciente em relação à sua experiência durante a internação hospitalar.

Referencias: What Is Patient Experience?. Content last reviewed March 2017. Agency for Healthcare Research and Quality, Rockville, MD. http://www.ibes.med.br/voce-sabe-o-que-e-experiencia-do-paciente/ 